\title{
Generalism for specialists: a medical reformation
}

\author{
Kamran Abbasi executive editor
}

The BMJ

Reform of medicine is urgent and necessary. Increasingly, patients have two or more conditions at the same time, but clinicians are devoted to one disease, body part, or organ. Training, clinical teams, guidelines, and research are focused on an isolated component. An intellectual shift is required to think of multimorbidity as predictable clusters instead of a random assortment of individual parts. And that sea change is the revival of generalism, even for specialists.

It is possible and desirable to be both a specialist and a generalist. But other than a few specialties, such as general practice, geriatrics, and diabetes, we have ploughed too deeply the furrows of vertical care, instead of treating people as a functioning whole.

"The pattern of health and disease in our population is changing, and as a profession we must respond." These are the words of the four UK chief medical officers, of presidents or chairs of the royal colleges of general practitioners, physicians, and surgeons, of leaders of the NHS, GMC, educators, and medical schools (doi:10.1136/bmj.16964). This is as impressive a list as you will find in any authorship group in The BMJ's 180 year history, and they present a hard case to argue against. The shift back to generalism should accelerate, they say, and be a greater focus in selection, training, and reward of the future workforce.
By doing so, by caring more holistically, we might create a happier workforce. Rammya Mathew asks why doctors are so unhappy (doi:10.1136/bmj.m100). Why do we deter our friends and family from following in our footsteps? Unhappiness among doctors isn't a new phenomenon, but medicine has become a daily grind of to-do lists, patient lists, and bed numbers. To reignite our passion for our profession, to talk about our careers with pride, argues Matthew, we must "put people back at the heart of everything we do."

We might also consider the French approach of stopping funding for treatments of statistically significant benefit but uncertain clinical effect (doi:10.1136/bmj.16930). Two years ago France delisted dementia drugs from state reimbursement, arguing that drug treatment diverted attention from ensuring adequate support for patients and care givers. Invest in the person, say the French, rather than drug treatment of limited effectiveness.

In the meantime, as we wait for medical practice to be reformed by the good and the great, you might wish to seek recognition for your excellence in patient care by entering this year's BMJ Awards (thebmjawards.bmj.com). The closing date is 24 January. 